\title{
Organizing vocational education and training in schools: A case study of Australian Governments' educational policies
}

\author{
Guihua Cui \\ Foreign Languages College - Jilin University \\ Jilin, Changchun, China
}

\begin{abstract}
Australian Governments of different levels have initiated and carried out some policies to reform vocational education and training in schools to ensure school to work successful transition. This article takes the New Framework as the target policy for analysis, supplemented by other related policies to investigate Governments' purposes, principles and measures for organizing vocational education and training in schools. Dramaturgical coding method, together with excerpt-commentary analysis, has been adopted in the policy analysis. It is found that the partnerships among different levels and different agencies are key to the organizational changes in the success of vocational education and training in schools in effecting a seamless work/study transition. This approach offers an informed representation of the information that is conveyed in the New Framework by vividly interpreting its terms and conventions. The most important factor promoted by these policies was the promotion of partnerships between schools and industries.
\end{abstract}

Key word: VETiS; government policy; dramaturgical coding; organizational change

\section{INTRODUCTION}

Over the last decade Australian Governments at state and federal levels have issued different policies to reform Senior Secondary schooling through vocational education and training (VET) or vocational education and training in schools (VETiS), thus named in this research as VET/iS. This choice of terms has been done in part because the policies issued by the Governments are directed to both VET and VETiS, and in part because VET and VETiS are interrelated. Therefore, in this research these two terms are merged as VET/iS. The analysis of these policies in this research provides insight into the Governments' aims, attitudes and strategies for organizational changes through VET/iS in different dimensions. Macro policy, when it is effective, can result in micro changes (to school-level practices) that are consistent with the changes desired by policy makers. A researcher's task is "not to minimize or underestimate the effects of policy" (Ball, 1994:11), but to interpret what the policy-makers try to convey to the policy readers. For these reasons, such an analysis is critical for school organizational changes through VET/iS, and also the diverse policy issues concerning VET/iS enhancement. This is because VET/iS is regarded by policy makers and schools as "an important way to both retain students in school, provide pathways between education and employment through the provision of employment related skills and to increase the skills base of the economy" (Stokes \& Wyn, 2007:503).

While policy paradoxes and ambiguities are not unique to education, the consequences for young adults are particularly important. In education settings it is expected that the most significant policies will create changes "intended to improve the educational outcomes for the majority of students, with the greatest benefits of change flowing to those for whom the system has traditionally worked least well" (Crump \& Stanley, 2005:8). Under such circumstances, we 
intend to explore what are Australian Governments' principles, initiatives and strategies conveyed in the policies issued in terms of organizational changes in schools through VETiS? This research investigates these and related issues by analyzing four VETiS related policies, namely

1. New Framework for Vocational Education in Schools: A comprehensive guide about pathways for young Australians in transition (MCEETYA, 2001)

2. Shaping Our Future: Australia's National Strategy for vocational Education and Training 2004-2010 (Australian National Training Authority (ANTA), nd)

3. Queensland Skills Plan 2008 (Queensland Government, 2006)

4. National VET Sector Sustainability Policy and Action Plan (2009-2012) (National VET Sector Sustainability Action Group \& Ministerial Council for Vocational and Technical Education (shortened for Action Group \& Ministerial Council, nd)

Four policies were chosen for analysis because "one policy paper is unlikely to reflect perfectly the range of official policy statements made on a specific issue" (van Eeten, 2007:253). The purpose of analyzing these policies is to better understand and interpret the information and implied meaning each policy conveyed to policy readers and to explore what the policies say explicitly or implicitly - about organizational changes in Senior Learning as a result of VET/iS. These policies are the representatives of a certain position or phenomenon at the collective level. Another reason for this policy analysis is that "the success of VET in Schools has a number of consequences that have not yet been fully acknowledged or researched" (Smith, 2004:560). Even so, at a national level, the Australian Student Traineeship Foundation (ASTF) was set up "to encourage more work placements for senior school students", and at State and Territory levels, Education Departments set up special units "to develop and monitor VET in schools programs" (Smith, 2004:563).

Education policy is "an investment in the individual lives of a younger generation by an older generation to ensure hopeful futures both for individuals and for society as a whole" (Bardsley, 2007:504). Education policy is developed and applied to address students' current and future needs. Policies impact on citizen attitudes and behaviors "through the messages, models and actual allocation of values for the society" (Schneider \& Ingram, 2007:329). They are expected to address issues through the process of policy implementation. We will start with governments' motives for producing VETiS policies in Queensland.

\section{GOVERNMENTS' MOTIVES FOR PRODUCING VET/IS POLICIES}

Secondary schooling in Queensland was restructured through policy interventions as a result of difficult collaborations between industry, the unions and the Government (Crump \& Stanley, 2005). The objective of this collaboration was to improve educational and economic outcomes for young adults in Queensland through recognition of broader competencies and qualifications. One specific objective was to increase the retention rates in senior secondary education by encouraging young adults to 'stay on' (or return) to complete senior school and/or further education and training. Each year, each participant was supposed to be either enrolled in high school; or studying full-time or part-time at a university; or studying full-time or part-time in TAFE or another form of vocational training; or in an apprenticeship or a traineeship; or working full time or part-time and not in study; or unemployed, or not in the labour force (Vickers, Lamb \& Hinkley, 2002:6).

Te Riele (2007) observes that there were about a quarter of young adults in Australia who did not complete Year 12 in 2002. This is much lower than the Government's target of 90 percent of young people having completed Year 12 or an equivalent by 2015 (MCEETYA, 2008). 
Because a quarter of young adults are a concern to Governments, system-wide innovation was proposed:

By 2006, all Year 10 students, or those who were 15-years-old [would] be registered with the newly formed Queensland Studies Authority. New legislation requires young people to remain at school until they finish Year 10 or have turned 16, whichever comes first. All young people engage in a compulsory two-year participation phase of either learning and/or earning activities (Queensland Government, White Paper cited in Harreveld \& Singh, 2007:274-275).

In this case VETiS was created as "a key link in this chain of planned events" (Crump \& Stanley, 2005:1). This meant young adults were offered more 'second chance' options through Government policies to increase the retention rate. The policy New Framework (MCEETYA, 2001) embraced the need for organizing improved transition pathways for all young adults from school to work, further education and training. This New Framework was developed in 2000, but as its core, it has a New Framework for vocational education in schools which is directly related to the topic of this research.

This New Framework features eight basic attributes, namely explicit and well-articulated pathways, community partnerships, lifelong learning skills and attributes, enterprise and innovation, career information and guidance, and access to student services, individual assistance for students-at-risk, supportive institutional and funding arrangements, monitoring and evaluation (MCEETYA, 2001). These features offered a comprehensive guide for organizing pathways for young adults to make the transition from school to work or further education and training. There has been no revision to the New Framework since 2001, so this policy was chosen for analysis in this research. To explore the organizational changes in VET/iS expressed or implied in this policy, the six Key Elements of this policy are each analyzed, supplemented with evidence from three related policies (ANTA, nd, Queensland Government, 2006, and Action Group \& Ministerial Council, nd), using creatively research methods of dramaturgical coding (Saldaña, 2009), which is originally used to code drama, and 'excerpt-commentary' analysis (Emerson, Fretz \& Shaw, 1995) respectively.

\section{GOVERNMENTS' ACTIONS IN ORGANISING SENIOR LEARNING THROUGH VET/IS}

For policymakers, conceptualizing vocational learning in ways that mirror formal education enables them to "set standards for the design of vocational qualifications, allocate funding, measure outputs and compile data on the volume of skills in the economy" (Unwin \& others, 2007:336). But policy is seen as an open-ended process of change or growth in a hierarchical context. There is no guaranteed direction for change. All policy ideas have the potential "to improve or make worse the issue they are addressing" (Crump \& Stanley, 2005:7).

\section{Principles and purposes of organising VET/iS}

Policies may provide benefits that make a difference in young adults' work/study trajectory, and they give the rationales, rules and tools for implementing organizational structures through which recipients have "direct experience with government operatives" (Schneider \& Ingram, 2007:341). In the New Framework (2001) for VETiS, the first Key Element provides for young adults the organization of accredited industry-specific training based on the Australian Quality Training Framework (AQTF), qualifications and competencies endorsed within the National Training Framework. 


\section{Key Element 1}

VET/iS programs have emerged as ${ }^{1}$ a major pathway for senior secondary students in recent years. The next major stage in the development of this pathway is ${ }^{2}$ to ensure that VET/iS programs become a fully integrated and sustainable feature of senior secondary schooling.

The achievement of sustainability across government and non-government school sectors in all states/territories represents 3 the next major challenge for VET/iS programs.

VET/iS programs will ${ }^{4}$ comply with the Australian Recognition Framework (ARF) and ${ }^{5}$ progressively implement training packages. Qualifications delivered through VET/iS programs will ${ }^{6}$ need to be indistinguishable from qualifications delivered by other providers. The progressive introduction of training packages on an industry basis indicates that the transition to full implementation ${ }^{7}$ will take a number of years.

VET/iS qualifications ${ }^{8}$ will be recognised for tertiary entrance purposes and will be ${ }^{9}$ increasingly accepted in the Employment market. In order for VET/iS pathways to 10 be accessible for all students it is 11 necessary to establish satisfactory arrangements concerning tertiary entrance. Some progress has been made in this area but there is a need for more 12 universal application. Acceptance of VET/iS qualifications in the employment 13 market requires employer confidence in the quality assurance arrangements.

To ${ }^{14}$ further expand opportunities for school students through this pathway 15 a number of issues require

16 further attention. (MCEETYA, 2001),

\section{Analysis}

${ }^{1}$ Att: major pathway

2 Obj: ensure integration and sustainability

3 Con: challenge

4 Tac: observance

5 Tac: implementation

${ }^{6}$ Emo: equality of VET/iS qualification

${ }^{7}$ Con: taking time

8 Obj: recognition

9 Obj: market acceptance

10 Obj: accessibility

11 Tac: arrangements

12 Att: universally applicable

13 Con: requirement

14 Obj: opportunity expansion

15 Con: issues

16 Sub: unsolved

The principle of this Key Element is to organize the full integration and sustainability of Senior Secondary Schooling through VETiS. Organizing this phase of schooling in this way is meant to benefit all students. Specifically, it aims to organize the recognition and the acceptance of VET/iS qualifications in the labor market, expanding opportunities to ensure VET/iS students' better transition from school to work. This is because it is believed that VET/iS can become a major pathway for young adults. Organizing VET/iS through the qualification framework 
means it is applied universally. There are, however, issues which may hinder the progress of this action, with major challenges being the time it will take to realize this goal and to meet employers' requirements.

Strategies to organize VET/iS accessible involve adopting the Australian Recognition Framework (ARF) and implementing training packages. The motive driving these strategies is that VET/iS qualifications need to be regarded as equal to academic qualifications. This Key Element implies that some organizational issues remain unresolved for implementing and increasing opportunities of VET/iS pathways for young adults which need to be further explored. For instance, the assumption that "the majority of young people are doing well and policy merely needs to target the small number of young people who are 'at risk, disconnected or in vulnerable circumstances'” (te Riele, 2007:56), is questionable because this Key Element clearly states VETiS pathways are for all students to access. Possibly this pathway may be more feasible for those allegedly 'at risk', but it is not soly for them.

In 1999, the Australian Ministerial Council for Education, Employment, Training and Youth Affairs (MCEETYA) defined VETiS as:

VET in Schools programs are undertaken as part of a student's Senior Secondary Certificate and provide credit towards a nationally recognized VET/iS qualification. VET in Schools programs are based on national industry competency standards (MCEETYA cited in Dalley-Trim, Alloway, Patterson \& Walker, 2007:28-29).

VETiS is used to provide skills and knowledge for work, enhance employability prospects and assist further education and training as the following policy states.

Evidentiary excerpt

This National Strategy is a commitment to continue to work in partnership with industry, providers and other stakeholders to develop vocational education and training. Vocational education and training is a vast activity involving a rich, dynamic and diverse range of individuals and organisations. This national strategy sets a vision, four objectives and 12 strategies for vocational education and training at the national level until the end of the decade (ANTA, nd:3).
Key concept

Principle and action

The principle of this New Strategy (nd) is to continue the partnership being engaged with different sectors. In this policy VET/iS is considered a significant event which needs diverse participants. The richness, dynamic and diversity of the participants are salient characteristics of VET/iS success. The National Strategy (nd) provides the tactics in the form of a vision, four objectives and 12 strategies for VET/iS at national level. This National Strategy (nd) applied from 2004 to 2010. According to this Strategy, industry decides key aspects of VET/iS, and the clients of VET/iS include full-time and part-time students, apprentices, and trainees. It offers long-term objectives and strategies for making VET/iS client-driven. This is supposed to make VET/iS better respond to the multiple and diverse needs of all parties and provide the basis for organizational changes that respond to and give expression to a rapidly changing world.

VET/iS is meant to enhance Australia's success in the competitive world economy by working together on a nationally coordinated approach. The following evidentiary excerpt captures this Australian view of VET/iS. 


\begin{tabular}{l|l} 
Evidentiary excerpt & Key concept \\
\hline Vocational education and training has played an important role in Australia's & VET/iS \\
outstanding economic performance, by greatly increasing the skill of workers. & perception \\
The Australian approach to vocational education and training is now & \\
recognised as among the best and most innovative in the world (ANTA, nd: 5) &
\end{tabular}

Two significant points about VET/iS are conveyed in this policy. First, VET/iS had an important role in Australia's economic performance through providing with skilled workers. Second, VET/iS is an innovative approach which is valued where successfully implemented. The decisive elements for the success or failure of the implementation of VETiS are indicated in the following excerpt:

\begin{tabular}{l|l} 
Evidentiary excerpt & Key concept \\
\hline High-quality, accessible and innovative VET/iS has never been more & VETiS quality \\
important. The capacity of individuals to work effectively and safely and & and capacity \\
engage with society, the competitiveness of industry, the adaptability of & \\
communities, regions and the nation - will all depend on Australia's & \\
education and training capacity (ANTA, nd:7). &
\end{tabular}

In Australia, VET/iS is expected to play a key role in enhancing the capacity of young adults, the competitiveness of industry and the adaptability of the different organizations involved in this strategy. The quality, accessibility and innovativeness of VET/iS as advocated in this National Strategy (nd) is driven by concerns about industries facing even stronger international competition. The challenge is increased because manufacturing industries are expected "to employ a smaller percentage of all workers", and the number of jobs in construction, agriculture and mining is also "expected to fall" (Access Economics cited in ANTA, nd: 6). In addition, young adults find transition from school to work challenging. VETiS was proposed to meet these challenges, emphasizing "quality and capacity in training and assessment, and portability of skills between occupations, industries and locations" (ANTA, nd:7).

The claim that the purpose of VETiS proposed "has never been clearly articulated; even within the context of schooling alone it is unclear what it is meant to do" (Smith, 2004:570), is an overstatement. The analysis of the evidence above indicates that the purpose of VETiS has been stated in Government policies, including their corresponding strategies. Moreover, Biddle (2007:179-180) claims that significant changes have occurred in Senior Secondary Schooling whereby,

university education has become a reality for a much larger segment of the population and finishing high school has become the absolute minimum entry requirement for many jobs. This has resulted in large increases in student population and school retention rates.

According to this claim, VETiS can offer benefits for both students and schools. The benefits for students include:

1. the chance to gain a VETiS qualification, as well as pass school subjects;

2. the choice of a more 'hands-on' subject, which might suit them better than academic subjects;

3. for those not gifted academically, the chance to shine at something;

4. positive employment outcomes after leaving school (Fullarton cited in Smith, 2004:570).

Schools also experience the benefits, including the following:

1. increased retention rates by offering a broader curriculum; 
2. increased attractiveness to students about to enter Year 11 and their parents;

3. establishment of beneficial relationships with local employers;

4. students who are more interested in their studies and therefore easier to manage (Smith, 2004:570)

VET/iS may also benefit Australia's 'green economy'. This is because the transition to a low carbon, sustainable economy - green economy - requires workers with new skill sets and values sympathetic to the environment.

\begin{tabular}{l|l} 
Evidentiary excerpt & Key concept \\
\hline Existing jobs will need to be transformed as individual firms and entire & Green jobs \\
industries move to a low carbon, sustainable economy. 'Green jobs' provide & \\
opportunities for career advancement through increasing and diversifying & \\
the skills a worker requires. (Action Group \& Ministerial Council, nd, np) &
\end{tabular}

Entirely new categories of 'green jobs' are expected to be created. It is estimated that around 2.5 million 'green jobs' will be created in Australia over the years to 2025, and 7.5 million by 2050 (Hatfield-Dodds, Turner, Schandl \& Doss, 2008).

Even so, there is room for improvement in VET/iS since problems and issues still exist in areas of student satisfaction and pathway, as the following excerpt indicates:

\begin{tabular}{l|l} 
Evidentiary excerpt & Key concept \\
\hline Clients still see VET/iS as complex, and this denies them the ability to make & VETiS issues \\
informed choices about the 'what, where, when and how' of training. The & \\
availability and quality of VET/iS varies between and within States and & \\
Territories, and it is still concentrated in only a few industries (ANTA, nd:10). \\
Pathways between education and training sectors have improved but \\
barriers still exist, particularly between VET/iS and universities (ANTA, \\
nd:11).
\end{tabular}

Although VET/iS has been successful in many fields, there are still some issues that need investigation. VET/iS is complicated for some young adults, impacting on their work/study choices. Additionally, there are only a few industries engaged in VET/iS, and the access to and the quality of VETiS vary across different States. For instance, obstacles exist between VET/iS and universities for young adults, whereby the latter consider VETiS to be a 'soft option'. All these may prevent VET/iS from successful implementation and realizing its potential popularity.

The introduction of VETiS presents significant changes to Senior Secondary Schooling. VET/iS programs aim to "provide young people with better links to industry, and more diverse pathways from school to work and further study, [and] expand opportunities for Senior Secondary students, and to prepare young people for the workplace of the future" (Anlezark, Karmel \& Ong, 2006:13). Nearly every secondary school in Australia now offers VET/iS programs. These programs can be undertaken in a variety of ways:

1. Students study the entire qualification within the school and the school awards the VET/iS qualification, if it is accredited as a Registered Training Organization.

2. Students study at school and the school has a partnership with an outside RT0, which oversees the quality of the training and issues of the qualification.

3. Students study the VET/iS-qualification-related part of their course at a local TAFE college or other RTO; in this case, the school 'purchases' the training from the RTO (Smith, 2004:566). 
The accessibility and availability of these programs have been increased because VETiS is popular among young adults.

\section{Integration of l/earning: Government's strategies for organising students' transition}

Key Element 2 in the New Framework (2001) focuses on the integration of enterprise and vocational perspectives into the l/earning that is suitable to young adults' schooling.

\section{Key Element 2}

A major focus within this element is to

1 enhance the transitions for all young people ${ }^{2}$ through access to generic skills and competences. ${ }^{3}$ These are valuable to

${ }^{4}$ all students throughout their school life.

The development and attainment of these skills also ${ }^{5}$ contributes to the selection of VET/iS programs in senior secondary schooling.

A further focus within this key element is

${ }^{6}$ access to enterprise education programs and activities. Opportunities for involving young people in enterprise education programs and activities will be

7 identified and implemented.

(MCEETYA, 2001)

\section{Analysis}

1 Obj: enhance the transitions

2 Tac: accessibility to skills

3 Emo: valuable

${ }^{4}$ Sub: beneficial to all

${ }^{5}$ Att: conducive

6 Obj: accessibility

${ }^{7}$ Tac: identification and implementation

This evidentiary excerpt indicates the aim of enhancing the transitions from school to work or further education and/or training for all - or more - young adults by providing generic skills training and organizing enterprise education programs so that these are accessible and available to them. The rationale is that skilled jobs dominate jobs growth and young adults with vocational education and training qualifications "fare much better in the employment market" (MCEETYA, 2008:4). Therefore, Australia's young adults are now encouraged to complete secondary education and also to proceed into further training or education. The strategies taken to realize this outcome focus on the identification and implementation of opportunities for learning generic 'green' skills that enhance young adults' employability. The policy assumption is that having young adults choose VET/iS programs and activities will be valuable for their work/study trajectory. What is implied in this Key Element is that the generic skills and competences are extremely important and conducive to all - or most - young adults' future employment. 'Green' skills are important for this rising generation of workers, as the following excerpt states:

\section{Evidentiary excerpt}

Key concept

The specific skills that the low carbon, environmentally sustainable Green skills economy demands will need to be continuously identified to ensure that the VET sector invests in designing and delivering new training programs and retooling existing training programs to meet the expected demand. (Action Group \& Ministerial Council, nd)

VETiS is expected to develop new skilled workers for innovative technologies through supporting or creating arrangements for knowledge sharing and partnerships. To build transition from school to work, vocational training and university education, school-industry 
engagement continue to be developed. As the following evidentiary excerpt states, this requires action to accord with different projects:

\begin{tabular}{l|l} 
Evidentiary excerpt & Key concept \\
\hline The action will be streamlining school-based industry relationships; & school-industry \\
implementing Gateway Schools projects that include agribusiness; building & partnerships \\
and construction; manufacturing; and sharing best practice and capturing & \\
innovative projects at the local, regional and state level (Queensland & \\
Government, 2006:19). &
\end{tabular}

Three points in this excerpt are noteworthy. First, the school industry relationships are being reorganized. Second, plans are needed for projects in different industries. Finally, best practices at different levels have to be captured so innovative projects are shared. Young adults at school are given the chance to experience different trades to broaden their understanding of the opportunities these careers can offer. The "Try'a Trade program" enhanced the partnerships between schools and industry (Queensland Government, 2008:18).

The implementation of 'Try'a Trade' could delay young people's acquisition of vocational preparation, rather than having them undertake credential-based vocational education and training (Taylor, 2005). Organizational changes in schools have focused on providing industryspecific work skills and associated competencies so that school students access to qualifications that industry needs. But an apparent consequence of this may be that students have to make initial career choices at a much earlier age. For instance in Western Australia, it is recommended that "school-based vocational training be made compulsory as part of the Year 8 to 12 secondary school curricula" (Curriculum Council cited in Taylor, 2005:213). If this locks young adults into a single track, then this recommendation is questionable. Taylor $(2005: 213)$ argues that "if it is put into action, the direction of school education will be changed, at least from Year 8 on". This claim is debatable. Making an explicit link between manual and intellectual labor could be productive. Learning generic vocational skills could be valuable for all students if it includes academic and vocational studies, and could be beneficial throughout their life.

The conception of youth-in-transition is built on the idea of "a forward momentum that carries individuals from the status of student (immaturity) to vocation (maturity)" (Stokes \& Wyn, 2007:498). However, policy approaches that focus only on the links between study and work tend to "over-emphasize the linearity of this process and its direction" (Stokes \& Wyn, 2007:498). The assumption of linear movement from one dimension (study) to another (work) supports the idea that "these are distinct and dichotomous fields and that learning occurs at a set time and within a distinctive site that is age-based (formal schooling)" (Stokes \& Wyn, 2007:498). While some have argued that linearity continues to represent the trajectories of 'successful' youth transitions, Stokes and Wyn (2007:498) suggest that "this concept of linearity must take a very broad approach to the relationship between study outcomes and employment destinations". Disjunctures between fields of study or areas of qualification and occupation, and breaks in the timeline can not be ignored. In practice, learning (study) and earning (work) are now far more interrelated in young adult's lives, whether they be at school, college or university. That is to say, learning can occur in many different sites and is often "conterminous with employment" (Stokes \& Wyn, 2007:498), even in the lives of secondary school students. The integration of learning and earning is expected to provide young adults with more options and opportunities. With more options created through VETiS Senior Secondary schooling is being changed for better but not for worse. 


\section{Governments' strategies for organising students' support services}

Governments of different levels proposed several strategies for better organizing young adults' support services. A major area of growth in VETiS has been school-based apprenticeships, with 211900 students enrolled in 2004 in VETiS, including 15200 school-based apprenticeships commencements in 2005 (NCVER, 2008). The following excerpt suggests that this growth indicates the success of the implementation of VETiS:

\begin{tabular}{l|l} 
Evidentiary excerpt & Key concept \\
\hline $\begin{array}{l}\text { Employer and student satisfaction is high. In 2001, 84\% of employers were } \\
\text { satisfied with the quality of graduates, and in 2002, 78\% of graduates } \\
\text { achieved their main reason for enrolling in their course (ANTA, nd:10). }\end{array}$ & Reciprocal \\
satisfaction
\end{tabular}

This mutual satisfaction comes not from 'skills' that employers require but a complex of attitudes, dispositions and affective traits. For example, Wooden (cited in Taylor, 2005:205) observes that "employers are ranking highly maturity, adaptability, trainability, initiative, cleanliness, good manners, interest in the job and respect for authority". Since all policies have the potential to improve the issue addressing (Crump \& Stanley, 2005), student support services are proposed to ensure better results.

Key Element 3 in the New Framework (2001) indicates the services that support young adults in their transition from compulsory schooling to post-school destinations and options. 


\section{Key Element 3}

Career education programs, activities and experiences will ${ }^{1}$ continue to be provided in schools ${ }^{2}$ to increase student awareness about ${ }^{3}$ the rapidly changing nature of work and careers.

The provision of ${ }^{4}$ readily accessible, well organised, accurate, comprehensive and current information is 5 a vital element of the new framework. This information is ${ }^{6}$ essential for all young people to be able to meet the demands of the knowledge economy. Information also ${ }^{7}$ needs to be broader and include careers and labour market information to enable students to ${ }^{8}$ make informed transition decisions.

The effective provision of this information involves

${ }^{9}$ schools cooperating with employers, employment services and other relevant organisations in gathering and disseminating local industrial trends and job opportunities. ${ }^{10}$ There is a growing realisation that ${ }^{11}$ not all of the necessary information is within schools and there is 12 a need for linkages to be established to ensure that young people have access. In addition to this, the production of high quality information in a variety of formats able to be used independently by ${ }^{13}$ young people is required.

${ }^{14} \mathrm{High}$ quality information services alone ${ }^{15}$ are not enough. Effective student support services ${ }^{16}$ require facilities which provide personal help and assistance.

${ }^{17}$ Case management approaches drawing on the professional counseling services available within the school and in the wider community ${ }^{18}$ are necessary to support many young people ${ }^{19}$ experiencing difficulties in transition. School-community partnerships will ${ }^{20}$ assist young people in transition by establishing arrangements. (New (MCEETYA, 2001)
Analysis

${ }^{1}$ Tac: continual provision

2 Obj: increase awareness

3 Con: rapidly changing

4 Obj: diverse information

${ }^{5}$ Att: vital

${ }^{6}$ Att: vital

${ }^{7}$ Con: need broadening/inclusion

${ }^{8}$ Obj: decision making

9 Tac: cooperation

${ }^{10} \mathrm{Att}$ : more and more awareness

11 Con: not all

12 Con: need for linkage

13 Con: need high quality information

14 Sub: additional strategies

15 Con: not enough

${ }^{16}$ Con: more requirement

17 Tac: available services

${ }^{18}$ Emo: essential

${ }^{19}$ Obj: overcome difficulties

${ }^{20}$ Tac: help

This Key Element aims to increase students' awareness of the labor market. The main obstacles to the achievement of this policy objective is the unstable nature of the job market for young adults; a factor that was especially evident with the beginning of the 2008 global financial crisis. The related issues are ways of organizing access to information for young adults about the labor market; producing high quality information about career and opportunities; and 
creating effective facilities for student support services. It is believed that increasingly more people from different sectors are becoming aware of these issues and are trying by different means to deal with them because this is vital to all young adults' transition to work and selection of VET/iS pathways. To tackle these issues, the key tactics are about encouraging exhorting - cooperation among different sectors including schools, employers and different organizations; and helping young adults prepare for the work by making student services available to all. While organizing partnership between schools and industry is crucial, Australian Governments also support a range of other strategies:

increasing access to and participation in high quality, industry-recognised training at Certificate III level for secondary school students, including through Trades Training Centers [and] ensuring all students have access to quality support, information and advice to facilitate access to further education, training, careers, and employment options (MCEETYA, 2009:12).

This Key Element implies that one strategy alone is not enough to deal with these issues. Multidimensional and multilevel engagements are needed to cope with the complexity of the issues. In addition to the partnerships, making student services available and accessible to all is also highly significant. Services are expected to be organized in the way to help young adults navigate and interact with vocational education and training effectively and successfully.

\begin{tabular}{l|l} 
Evidentiary excerpt & Key concept \\
\hline Clients, particularly youth in transition find VETiS more understandable & Servicing \\
and enjoy easier access to information, career development, navigation and & \\
brokerage services. & \\
Communities engage in partnerships with VETiS to meet their local \\
economic development needs (ANTA, nd:15).
\end{tabular}

This evidence suggests that VET/iS is popular among young adults who can access relevant careers information. Community engagement in VET/iS is also said to have local economic benefits. However, to make effective transitions from school to employment, young adults require not only access to information but also qualified people to assist them in making decisions about jobs, courses and career paths. Skilling Solutions Queensland was established by the Government as an organization to help them solve these problems.

\begin{tabular}{l|l} 
Evidentiary excerpt & Key concept \\
\hline A Youth Career Information Framework will be developed through an ICT- & VET/iS \\
based portal which craws together a range of career development products & doorway \\
and services to provide information for school students on VETiS & \\
programs. This will include information on: school-based apprenticeships & \\
and traineeships; VETiS options; and Skilling Solutions Queensland services & \\
(Queensland Government, 2006:18). &
\end{tabular}

This particular framework provides services about VETiS via ICT to young adults. The services offered are diverse, ranging from school-based training to VET choices. However, further measures need to be taken through creative partnerships to increase student participation in VET/iS, especially in school-based apprenticeships and traineeships. The training department worked with stakeholders "to double the participation in school-based apprenticeships and traineeships over the period 2006-2010" (Queensland Government, 2006:18). Expanding opportunities for pre-trade training was also of importance, and more pre-vocational training was to be delivered to enable young adults to "get a head start on their trade career" (Queensland Government, 2006:18). 
Increasing partnerships between the training and education sector was seen as vital for young adults' transition from school to work. To organize these partnerships the training department produced a professional development framework for the education and training sectors to share good practices and capacity building (Queensland Government, 2006). Queensland's education and training reforms suggest that "secondary schools can broker learning opportunities for young adults through youth support services; long-term flexible socioacademic learning services; networking to power through mentoring and work readiness training" (Harreveld \& Singh, 2008:13).

These learning organizations play an essential role in the construction of young adult's competence which is essential for their educational development and in supporting them to negotiate the complexities of education and labor market. However, more nuanced policy approaches are needed, supported by a more contextually grounded concept of transition which acknowledges "both the societal shift from industrial to post-industrial modes of learning and earning and the role that young people play in forging new identities and approaches to career" (Stokes \& Wyn, 2007:496). In the learning setting, there also need multiple forms of cooperation.

\section{Collaboration across different levels: Organisational changes in learning settings}

Key Element 4 in the New Framework (2001) centers on the mechanisms that promote close cooperation between all levels of Government, business, community organizations and education to address the issue of labor market.

\section{Key Element 4}

A major process for the implementation of the new framework is ${ }^{1}$ the application of community and business partnerships.

${ }^{2}$ The establishment and continuous development of partnerships between a wide and diverse range of agencies and groups concerned with young people is ${ }^{3}$ essential for the advancement of student outcomes.

${ }^{4}$ The centrality of partnerships is a further indication that increasingly learning takes place ${ }^{5}$ in a variety of ways and in a variety of settings. There is a substantial body of ${ }^{6}$ growing evidence that indicates school students achieve

${ }^{7}$ learning outside the school.

${ }^{8}$ Other important learning settings include training providers, workplaces and community organizations.

Government and non-government agencies at local, state-territory and national levels in partnership with business and the community will ${ }^{9}$ support and allow schools and local partnerships greater flexibility and authority. (MCEETYA, 2001)

\section{Analysis}

${ }^{1}$ Obj: partnership application

2 Tac: establish and develop

${ }^{3}$ Emo: vital to outcomes

${ }^{4}$ Att: centrality

5 Tac: various learning ways and settings

${ }^{6}$ Att: more and more evidence

${ }^{7}$ Sub: education venue

8 Tac: different learning settings

9 Tac: support and allow 
The objective of this Key Element was to organize collaboration between school, community and business. The attitude embodied in this Key Element is that organizing partnerships are central to broadening the ways and settings of learning, including learning outside schools because it is believed to be vital for the improvement of students' work/study trajectories. The organization and/or continued development of partnerships is recommended so as to enable learning to take place in a wide range of settings and in diverse ways, and to support and allow schools the authority and flexibility to create such partnerships. Similarly Australian Governments offer strategies for "partnerships with universities, registered training organizations, TAFE and businesses to broaden the horizons of students, support educators and provide students with links to further training, education and employment opportunities" (MCEETYA, 2009:12). This implies that schools are not the only place where young adults can receive education. Learning settings are diverse and flexible. On a similar point, the National Strategy identified objectives for involving different parties and individuals to improve and strengthen VET/iS. The following excerpt makes this point:

\begin{tabular}{l|l} 
Evidentiary excerpt & Key concept \\
\hline Industry will have a workforce to support strong performance in the global & Objectives \\
economy. & \\
Employers and individuals will be at the centre of vocational education and & \\
training. & \\
Communities and regions will be strengthened economically and socially & \\
through learning and employment. (ANTA, nd) &
\end{tabular}

One aspect of this evidence which is worth particular attention is that the strategy targeted people of different sectors. This indicates that people at different organizational levels need to be involved to improve and enhance VET/iS. As far as industry is concerned, its workers need to be equipped with skills to improve performance. As for communities and regions, VET/iS can not only motivate interest in learning but it strengthens "the capacity of TAFE and other providers and brokers to partner with local government and non-government agencies, businesses and industry clusters" (ANTA, nd:13). Local planning and innovation are encouraged to help communities deal with changes and take advantage of opportunities for growth.

The Queensland State Government first proposed the reforming of Senior Learning in 2003 with the release of proposal for education and training reforms. This offered "different governance structures, funding initiatives, certification procedures and qualification for senior phase learning and a repositioning of the senior secondary school as a broker of learning for young people" (Harreveld, 2007:275). The reform was expected to "create an educational, stimulating, and structured environment to promote growth and learning and to enhance school readiness" (Popkewitz, 2008:166).

The desired outcomes for this agenda were an increased number of young people who have successful transition into the Senior Phase of Learning, and successfully participate in a range of relevant options during the Senior Phase of Learning (DETA, nd). Facilitating their successful transition to further education, training and/or employment is a key focus. The possibilities for brokering learning opportunities for young adults provide "a basis for developing policies for Senior Learning that are based on knowledge of how education, training and work may be valued by individuals, and how they rank these relative to other goods they value" (Harreveld \& Singh, 2008:13).

Most States and Territories incorporate VET/iS administration within the one Government Department, but VET in Schools is typically administered through the school division. 


\section{Organisational changes in financial arrangements}

The national VET/iS system is strategically and politically positioned such that it is subject to major demands that go beyond those for skills that are industrially and occupationally defined. At the State and Territory level the VET/iS systems are primarily oriented to their historical function of "supporting industry skills formation and individual skill needs at entry and continuing levels" (Keating, 2008:13). Financially, VET in schools is funded through the school division, and this funding is not part of the State training profile. Under these arrangements the schools purchase training from TAFE or private registered training organizations (RTOs), or are themselves registered as an RTO. However, there are exceptions to this, whereby funding for VET in Schools is incorporated into the performance agreements of the TAFE institutes or colleges (Keating, 2008).

The proportion of the population doing VET/iS is increasing. In the last decade, enrolments in VET/iS have taken off. In 1991, just over one million Australian students were enrolled in VET/iS. By 2002, 1.7 million people were enrolled in this publicly funded system (NCVER cited in ANTA, nd:8), as the following excerpt states:

\begin{tabular}{l|l} 
Evidentiary excerpt & Key concept \\
\hline More than one in eight working-age Australians were doing vocational & Achievement \\
education and training, and three quarters of these were enrolled in TAFE. & \\
There was also particularly striking growth in VETiS: around 40\% of year & \\
11 and 12 students now do VETiS as part of their schooling (ANTA, nd:8). &
\end{tabular}

More and more young adults throughout Australia are choosing to do VET/iS through different ways. What is more important is that VETiS is becoming popular among young adults as part of their senior schooling. This indicates that people's view of schooling is not totally academically-oriented any more, and that young adults' pathways are not restricted to going to university. This provides a flexible transition with more pathways for young adults. With the increasing number of young adults doing VET/iS, the proportion of Australian employers that provide or support training for their employees also "increased from 61\% in 1996 to $81 \%$ in 2002" (ANTA, nd:9). More importantly, the number and variety of pathways into vocational education and training has "increased, especially for young people through New Apprenticeships and vocational education and training in schools" (ANTA, nd:9). The majority of publicly funded students attend TAFE. The organization of funding is an important factor affecting the implementation of VET/iS. The New Framework (2001) provides for effective program implementation through organizing financial arrangements for the continuous involvement of all relevant players at different levels. 


\section{Key Element 5}

${ }^{1}$ Arrangements are individually developed between the Commonwealth and each state/territory government system and non-government school authority to ${ }^{2}$ enable integrated and coordinated approaches to policy, planning, funding and service delivery.

${ }^{3}$ The coordinated and integrated arrangements will ${ }^{4}$ be tailored to the unique situation of each system and authority and ${ }^{5}$ recognize that they have different needs, histories, stages of development and policy emphases. Accordingly, these arrangements will be ${ }^{6}$ supportive of flexibility in local implementation.

The coordinated and integrated arrangements will ${ }^{7}$ be based on agreed performance measures that are ${ }^{8}$ outcome driven. These arrangements ${ }^{9}$ need to be broad based in order ${ }^{10}$ to encourage and facilitate greater stability in government funding, greater cooperation at the community level, and greater flexibility. (MCEETYA, 2001)

\section{Analysis}

1 Tac: individual arrangements

${ }^{2}$ Obj: integration/coordination

3 Tac: collaborated arrangements

4 Tac: modification

${ }^{5}$ Att: recognition

6 Emo: supportive

7 Tac: basis

${ }^{8}$ Sub: principle of arrangement

${ }^{9}$ Con: need broadening

10 Ojb: encourage/facilitate

This Key Element aims to organize integrated and coordinated approaches to policy, planning, funding and service delivery. This is due to the perception that the organization of the integration and coordination of partnership learning needs to be broadly based. People of different sectors have to be aware that these organizations have unique features, and to do this greater stability in funding from different levels needs to be encouraged and facilitated. Appropriately organized funding is necessary for achieving flexibility in implementation. The strategies that have been taken to invest in VET/iS means funding was to ensure VET/iS develops towards preferred direction:

\begin{tabular}{l|l} 
Evidentiary excerpt & Key concept \\
\hline Making a sustained investment in TAFE and other Registered Training & Building \\
Organizations. & \\
Enable training providers and brokers to partner with industry to drive & \\
innovation. flexible funding models and planning and accountability & \\
Implement flexibleaches. & \\
approacting & \\
Develop a sustainable mix of funding (ANTA, nd:16). &
\end{tabular}

What is important in this evidence is that Government investment in TAFE and RTOs is necessary to ensure the sustainability of the training sector, with partnerships between training providers and industry, making reforms in VET/iS possible. Flexible and sustainable Government funding is the key to organizational changes in VET/iS. In terms of resources, VET/iS courses are "more expensive to run than the non-VET/iS courses so their cost-benefit as a retention strategy has to be considered" (Stanley, 2007:97). This requires a sense of purpose which 
builds a more efficient and meaningful investment of people's intellectual, emotional, relationship and financial resources. Brokering changes based on such values can form, inform and transform the collective constituencies (Harreveld, 2007:282).

With sustainable investment and flexible funding, strategies for equipping young adults with 'green skills' are possible:

\begin{tabular}{l|l} 
Evidentiary excerpt & Key concept \\
\hline Better engagement with industry. & Engagement \\
Enhancing the capacity of the VET sector to deliver appropriate skills. & Enhancement \\
$\begin{array}{l}\text { Delivering flexible training, assessment and support services to skill and re- } \\
\text { skill the workforce. (Action Group \& Ministerial Council, nd) }\end{array}$ & Delivery
\end{tabular}

However, VET/iS funding still needs to be improved in some aspects even though much has been achieved, as the following excerpt suggests:

\begin{tabular}{l|l} 
Evidentiary excerpt & Key concept \\
\hline Strengthen industry's role in anticipating skill requirements and & Improvement \\
developing products and services to meet them. & \\
Making learning pathways seamless. & \\
Improve quality and consistency. & \\
Facilitate access to international markets. (ANTA, nd:17) &
\end{tabular}

This evidence shows that industry plays an important role in improving VET/iS. Learning/earning pathways need to be made effective and efficient while the quality and consistency of VETiS is a necessary focus of the improvement. Accessibility to international markets also needs to be possible. In order to make learning pathways seamless, partnerships between VET/iS and schools, universities and community education organizations are needed to combine education and training pathways. Partnerships with other sectors also help improve learning pathways (ANTA, nd). For example, at the national level, the Howard Federal Government claimed that "the ongoing liberalization of the economy, including education, is needed to maintain low taxes, essential for attracting multinational companies and their employees to Australia" (Bardsley, 2007:497).

Each Australian State has its own plans to promote and enhance its VET/iS. The Queensland Government's (2006) Queensland Skills Plan 2008 in Action claimed to mark a significant innovation in that State's vocational education and training system in 40 years. In this action plan, the Queensland Government (2006) expressed its intention to improve youth transitions between school, education and training to improve their education, training and employment outcomes, and to ensure young Queenslanders benefit from increased vocational opportunities. Completing Year 12 gives young adults opportunities for further education and employment. Recent reforms to education and training have focused on retaining young adults in education and training to age 17 in order to achieve a Queensland Certificate of Education, Certificate III vocational qualification or secure full-time employment.

\begin{tabular}{l|l} 
Evidentiary excerpt & Key concept \\
\hline $\begin{array}{l}\text { Improving youth transition to enhance education, training and employment } \\
\text { outcomes will be addressed through: } \\
\text { enhancing information and access to vocational education, training } \\
\text { and employment pathways }\end{array}$ & $\begin{array}{l}\text { Youth } \\
\text { transition }\end{array}$ \\
creating innovative partnerships between industry, education and \\
$\quad \begin{array}{l}\text { training } \\
\text { improving transitions for } 18 \text { to } 24 \text { years olds (Queensland } \\
\text { Government, 2006:17) }\end{array}$
\end{tabular}


Efforts to maintain the accessibility of VETiS pathways, and partnerships are necessary to support young people's transition through education to secure employment. However, a key policy issue is the financial support needed from different levels of Government. This is because as Bardsley (2007:500) notes that "the majority of Australian public schools, already significantly under-resourced in relation to private schools, saw valuable public funding for education being directed elsewhere" (Bardsley, 2007:500).

Moreover, the Howard Federal Government decreased funding for speciality Technical and Further Education (TAFE) colleges, developed to provide vocational skills, and increased funding for vocational education and training for those students in public schools who wish to choose an immediately applicable employment focus to their studies (Bardsley, 2007:502).

Australian Governments currently spend "around $\$ 3.8$ billion a year on vocational education and training and businesses a similar amount on training" (ABS, cited in ANTA, nd:6). Sustainable funding needs to be planned to deliver workers with the 'green skills' that the low carbon economy demands (Action Group \& Ministerial Council, nd, np). Interestingly, this points to the concept of 'skill' as being ambiguous due in part to the shifts over time and variations between different States. Australia has moved to reconsider and deal with the highly problematic issue of so-called 'soft skills', placing the issue on the vocational education and training agenda. A competency-based employability skills framework was developed to distinguish between so-called 'employability skills' (communication, team work, selfmanagement) and 'personal attributes' (loyalty, commitment, enthusiasm). The VET/iS sector has a critical role in "skilling new and existing workers, and supporting and creating other arrangements for knowledge sharing and partnerships" (Action Group \& Ministerial Council, nd, np). Rothstein (2007:195) argues that "policymakers have been very concerned with the relationship between high school employment and schoolwork. However, policy recommendations with respect to youth employment while in school have not been consistent over the years".

The evidence analyzed above indicates that Governments at different levels have been making efforts to prepare young adults for their l/earning including youth employment. The question then is how to measure these achievements? This evidence is analyzed in the following section.

\section{Measuring organisational changes}

The organization of the data collection is a necessary part of educational reforms providing evidence that enables the effectiveness of changes to be measured. 


\section{Key Element 6}

There will be ${ }^{1}$ a nationally agreed collection mechanism for ${ }^{2}$ gathering data about programs encompassed by the new framework. There is a recognition that data collection ${ }^{3}$ needs to be systematized to ${ }^{4}$ enable more effective measurement of the achievement of outcomes.

${ }^{5}$ More effective ${ }^{6}$ tracking and monitoring of young people will be implemented after they leave school.

${ }^{7}$ This is necessary in order

8 to identify students who become

${ }^{9}$ vulnerable or potentially at risk of not

making successful and ${ }^{10}$ help schools and school systems to assess their achievements in supporting young people's transitions. (MCEETYA, 2001)
Analysis

$1_{\text {Obj: nationally agreed }}$

2 Tac: data collection

${ }^{3}$ Con: need systematizing

${ }^{4}$ Att: more effective

${ }^{5}$ Sub: effectiveness

6 Tac: track and monitor

${ }^{7}$ Emo: necessity

8 Tac: identification

${ }^{9}$ Con: vulnerable and at risk

10 Tac: help

This Key Element aims to organize a nationally agreed mechanism for collecting data to measure outcomes. While it was suspected that some students had become vulnerable or 'at risk' of not making a successful work/study transition, there was no systematized collection of data about this. Therefore, tracking and monitoring young adults was seen as imperative to identifying needs so schools can help support students' achievements. It is implied that at the time, organizing the tracking and monitoring of young adults was not effective so needed to be enhanced. Progress towards the realization of monitoring changes at different levels and reporting these periodically was raised throughout the life of the National Strategy. The specific measures included:

\begin{tabular}{c|l} 
Evidentiary excerpt & Key concept \\
\hline 1. The level of student participation and achievement in VETiS & Key measures \\
2. The level of student employment outcomes and benefits after \\
training and their satisfaction with their training program \\
3. The level of employer adoption of, and satisfaction with, vocational \\
education and training in meeting the skill needs of their \\
workforce
\end{tabular}

Performance measures mainly focus on participation, achievement, employment and benefits of students; satisfaction of employers; awareness and engagement of the community; and the effectiveness of VET/iS system. These measures monitor and reinforce the implementation of VET/iS in Australia.

\section{CONCLUSION}

From the policies analyzed above, it seems that the partnerships among different levels and agencies are crucial to the organizational changes in Senior Learning and the success of VET/iS in effecting a seamless work/study transition. In Queensland, organizations were established as a 'bridge' to link schools and different industries, such as agribusiness, construction and building, manufacturing and engineering, wine tourism, and minerals and energy. 
This article has followed a different approach to analyse the policy documents that are fundamental to this research. It has explored the organizational changes implied in the New Framework for Vocational Education in School (2001), using a dramaturgical coding method (Saldana, 2009). This empirical approach to policy analysis helps to better understand the objectives, attitudes, conflicts, strategies, emotions, and implied meaning in this New Framework. This approach offers an informed representation of the information that is conveyed in the New Framework by vividly interpreting its terms and conventions. Another three related policies were analysed using excerpt-commentary analysis (Emerson, Fretz \& Shaw, 1995). The most important factor promoted by these policies was the promotion of partnerships between schools and industries.

\section{References}

Action group \& Ministerial council. (nd). National VET sector sustainability policy and action plan (2009-2012). Retrieved. from http://www.vta.vic.edu.au/docs/170209\%20NVSSPolicy\%20\%26\%20Action\%20Plan\%20Consult\%20draft.pdf.

Anlezark, A., Karmel, T., \& Ong, K. (2006). Have school vocational education and training programs been successful? NCVER, Adelaide.

Australian National Training Authority (nd). Shaping our future: Australia' national strategy for vocational education and training 2004-2010. Retrieved. from http://www.dest.gov.au/NR/rdonlyres/98206EC7-3B9A4A58-991F-4F28010BF825/16445/national_strategy.pdf.

Ball, S. (1994). Education reform: a critical and post-structural approach. Buckingham: Open University Press.

Bardsley, D. (2007). Education for all in a global era? The social justice of Australian secondary school education in a risk society. Journal of Education Policy, 22(5), 493-508.

Biddle, N. (2007). The labour market status of Australian students: who is unemployed, who is working and for how many hours? Journal of Education and Work, 20(3), 179-209.

Crump, S., \& Stanley, G. (2005). Integrating VET into the Senior School: Research findings on linear and non-linear pathways as a policy paradox. Paper presented at the Australian Association for Research in Education.

Dalley-Trim, L., Alloway, N., Patterson, A., \& Walker, K. (2007). Vocational education and training in schools: Career advisers' perceptions and advising practices. Australian Journal of Career Development, 16(1), 28-36.

Department of Education Training and the Arts (DETA). (nd). A guide to reviewing and revising district youth achievement plans. Retrieved. from http://education.qld.gov.au/etrf/docs/dyapguide.pdf.

Emerson, R., Fretz, R., \& Shaw, L. (1995). Writing ethnographic fieldnotes. Chicago: The University of Chicago Press.

Harreveld, B. (2007). The ETRF, robust hope and teacher education: making practical reforms to the senior phase of learning. Asia-Pacific Journal of Teacher Education, 35(3), 273-289.

Harreveld, B., \& Singh, M. (2008). Amartya Sen's capability approach and the brokering of learning provision for young adults. Vocations and Learning, 1(3), 211-226.

Harreveld, B., \& Singh, M. (2007). Queensland's education and training reforms for the future: the journey so far in senior phase learning. Brisbane, Qld: Department of Education, Training and the Arts.

Keating, J. (2008). Current vocational education and training strategies and responsiveness to emerging skills shortages and surpluses. Adelaide: NCVER.

MCEETYA. (2001). New framework for Vocational Education in Schools: A comprehensive guide about pathways for young Australians in transition Retrieved. from http://www.mceecdya.edu.au/verve/_resources/policy_file.pdf.

MCEETYA. (2008). Melbourne declaration on educational goals for young Australians. Retrieved. from http://www.mceetya.edu.au/.

MCEETYA. (2009). MCEETYA four-year plan 2009-2012: A companion document for the Melbourne declaration on educational goals for young Australians. Retrieved. from http://www.mceetya.edu.au.

NCVER. (2008). Australian vocational education and training statistics VET in Schools 2005. Retrieved from http://www.voced.edu.au/docs/ncver/statistics/86_16.pdf. 
Popkewitz, T. (2008). Cosmopolitanism and the Age of School Reform: Science, education, and making society by making the child. New York: Routledge.

Queensland Government. (2006). Queensland Skills Plan 2008. Retrieved. from http://www.trainandemploy.qld.gov.au/resources/information/pdf/skills-plan-2008.pdf.

Queensland Government. (2008). Next step Queensland 2008: A report on the destinations of Year 12 completers from 2007 in Queensland. Retrieved. from http://education.qld.gov.au/nextstep/pdfs/2008pdfs/nextstep08.pdf.

Rothstein, D. (2007). High school employment and youths' academic achievement. The Journal of Human Resources, 42(1), 194-213.

Saldaña, J. (2009). The coding manual for qualitative researchers. Los Angles: SAGE.

Schneider, A., \& Ingram, H. (2007). Public policy and democratic citizenship: What kinds of citizenship does policy promote? In F. Fischer (Ed.), Handbook of Public Policy Analysis: Theory, politics and methods. London: Taylor \& Francis Group.

Smith, E. (2004). Vocational education and training in schools in Australia: What are the consequences of moving from margins to mainstream? Journal of Vocational Education and Training, 56(4), 559-578.

Stanley, G. (2007). Education for work: the current dilemma of post-compulsory education. The Australian Educational Researcher, 34(3), 91-100.

Stokes, H., \& Wyn, J. (2007). Constructing identities and making careers: young people's perspective on work and learning. International Journal of Lifelong Education, 26(5), 495-511.

Taylor, A. (2005). What employers look for: the skills debate and the fit with youth perceptions. Journal of Education and Work, 18(2), 201-218.

te Riele, K. (2007). Educational alternatives for marginalised youth. The Australian Educational Researcher, 34(3), 53-68.

Unwin, L., Felstead, A., Fuller, A., Bishop, D., Lee, T., Jewson, N., et al. (2007). Looking inside the Russian doll: the interconnection between context, learning and pedagogy in the workplace. Pedagogy, Culture and Society, 15(3), 333-348.

van Eeten, M. (2007). Narrative policy analysis. In F. Fischer (Ed.), Handbook of public policy analysis: Theory, politics and methods. London: Taylor \& Francis Group.

Vickers, M., Lamb, O., \& Hinkley, 0. (2002) Juggling school and work: how students use part time jobs as they design their futures. Education Links Issues, 65, 19-99. 